Check for updates

The BMJ

Cite this as: BMJ2020;370:m3146 http://dx.doi.org/10.1136/bmj.m3146 Published: 06 August 2020

\section{Covid-19: 700000 patients could be left unable to see a GP face to face, charity warns}

\section{Abi Rimmer}

More than 700 ooo patients in England may be unable to get to face-to-face appointments because their GPs are at high risk from covid-19, a report from the Health Foundation has said.

Research conducted by the charity found that 7.9\% (3632) of all GPs and a third (209 of 639) of singlehanded GPs were at high risk of death from covid-19.

NHS England guidance suggests that NHS staff who are at potentially higher risk from covid-19 undergo risk assessment and have their activities adjusted accordingly, including ceasing face-to-face contact with patients. If singlehanded GPs were unable to see patients in person because of the risk to their health, 710043 patients would be left without physical GP appointments, the research found.

It also found that singlehanded practices run by a GP at high or very high risk from covid-19 were more than four times as likely to be located in the most deprived areas of the country.

Rebecca Fisher, a GP and senior policy fellow at the Health Foundation, said that this finding was particularly worrying. "Those are precisely the areas with the greatest health need, the biggest burden from covid-19, and an existing undersupply of GPs relative to need," she said. "Unless urgent action is taken this could become another way in which poorer communities become further disadvantaged, and risks further widening health inequalities.”

The foundation has said that clinical commissioning groups (CCGs) must ensure that they are aware of gaps in face-to-face provision of core general practice services in their localities. They must also work with practices and primary care networks to make sure that, where gaps are identified, arrangements are made so that all patients have access to face-to-face appointments, if needed, and without endangering GPs.

"Additional and ongoing funding may be required for primary care to enable practices to 'buy in' locum GP support for face-to-face-consultations," said the charity. "Failure to adequately assess the extent of the problem, and to provide sufficient funding to engineer solutions, is likely to further exacerbate existing health inequalities."

Responding to the findings, the chair of the BMA's General Practitioners Committee, Richard Vautrey, said that the research highlighted the need for more GPs, especially in deprived areas, as well as the continued provision of effective personal protective equipment and access to comprehensive occupational health services for GPs.

"Patients should not be left to worry about being unable to see their doctor in person, but neither should GPs be put at risk or feel unsafe," Vautrey said.

"Following significant pressure by the BMA the government has finally released funding to support the additional costs of responding to the pandemic for general practice, but we now need CCGs to provide the necessary support to those working in isolation, both for their own health and that of their patients.”

1 Health Foundation. How might covid-19 affect the number of GPs available to see patients in England? 6 Aug 2020. https://www.health.org.uk/news-andcomment/blogs/how-might-covid-19-affect-the-number-of-gps-available-to-see-patients-in.

This article is made freely available for use in accordance with BMJ's website terms and conditions for the duration of the covid-19 pandemic or until otherwise determined by BMJ. You may use, download and print the article for any lawful, non-commercial purpose (including text and data mining) provided that all copyright notices and trade marks are retained. 